\title{
Study of Interleukin-6 as an Indicator Biomarker in Perinatal Asphyxia
}

\author{
Tajuddin Mohd ${ }^{1 *}$, Iqbal R Kaur², Bineeta Kashyap², MMA Faridi³ and NP Singh² \\ ${ }^{1}$ Department of Microbiology, Delhi State Cancer Institute, Delhi, India \\ ${ }^{2}$ Department of Microbiology, UCMS \& GTB Hospital, Delhi, India \\ ${ }^{3}$ Department of Pediatrics, UCMS \& GTB Hospital, Delhi
}

\begin{abstract}
Background: Birth asphyxia, though not always a recognizable cause, is a well documented contributor to perinatal and neonatal mortality. Four million babies are born asphyxiated annually resulting into $20 \%$ of all neonatal deaths. Perinatal asphyxia is the fifth largest cause of under-5 deaths

Methods: Serum IL-6 levels were measured by ELISA in sera of thirty newborn babies $\geq 31$ weeks of gestation with Apgar score $<8$ at 1 minute after birth with perinatal asphyxia (Study group) and 30 age and sex matched healthy controls (Control group), at birth (within 6 hours) and 48 hours after delivery.

Result: The mean levels of IL-6 in the study and control groups were $158.09 \pm 63.76 \mathrm{pg} / \mathrm{ml}$ and $41.57 \pm 71.23 \mathrm{pg} / \mathrm{ml}$ at birth and $187.96 \pm 30.31$ $\mathrm{pg} / \mathrm{ml}$ and $24.54 \pm 58.74 \mathrm{pg} / \mathrm{ml}$ at 48 hours respectively. Rise in levels of IL-6 in study group when compared with the control was statistically significant both at birth and at 48 hours. The median IL-6 levels in the study group and control group were $196.40 \mathrm{pg} / \mathrm{ml}$ and $4.17 \mathrm{pg} / \mathrm{ml}$ respectively at birth. The median IL-6 levels in the study group at birth were 47 fold higher than levels of control group. Median IL-6 levels both at birth and at 48 hours were statistically not significant among the mild, moderate and severely asphyxiated neonates. Amongst 30 healthy neonates, IL-6 levels were statistically not significant both at birth and at 48 hours.

Conclusion: IL-6 levels were significantly raised at birth and after 48 hours in asphyxiated neonates compared to gestational age and sex matched healthy neonates.
\end{abstract}

Keywords: IL-6; Neonates; Perinatal; Asphyxia; 48 Hours

\section{Introduction}

Perinatal asphyxia is the lack of oxygen and/or blood supply to the developing brain that could end in permanent neurological damage due to hypoxicischemic encephalopathy (HIE), most of the events relating to intrapartum insults.[1] It is estimated that, in developed world 1/1000 live births, and 5-10/1000 live births in developing world suffer asphyxia perinatally. Approximately more than four million neonates are annually affected by severe perinatal asphyxia worldwide out of which around $20 \%$ die, and another $20 \%$ develop clinically significant sequelae.[2] In India, according to the National Neonatal-Perinatal Database 2002-03, asphyxia contributed to $29 \%$ of neonatal deaths.[3]

The topography of injury correlates with areas of hypoxia and ischemia which results into anaerobic metabolism and generates high levels of lactate and inorganic phosphates. Toxic molecules and free radicals accumulate in the damaged tissue.[4] Hypoxic-ischemic brain injury after severe birth asphyxia remains a clinical problem despite improvements in obstetric and neonatal care.[5]
Though several critical factors have been defined despite the complex pathophysiology of HIE, the elaborate mechanisms of brain injury and the significant mediators are largely unknown. [6-8] It is of utmost significance to increase the understanding of the events leading to brain injury and to identify early markers predicting outcome after birth asphyxia.

To the best of our knowledge, there is paucity of studies that have evaluated the association between hypoxiaischemia and release of cytokines among Indian neonates. Therefore, the purpose of the present study was to investigate if serum IL-6 concentrations could be used as an indicator marker of perinatal asphyxia in neonates. IL-6 is a commonly available parameter but cost could be a problem in a proportion of population. Cytokines modulate apoptosis of CNS cells. Though the exact role of IL-6 is unclear.[9] Other than CRP and Ferritin other acute phase reactant markers like procalcitonin are costlier.

IL-6 estimation is helpful in differentiating the perinatal asphyxia babies from the healthy babies and the levels are significantly associated with severity of perinatal asphyxia 
and HIE at birth. Hence it could be used as a marker for appropriate medical interventions to avoid progression to HIE. Early diagnosis and early intervention can lead to better outcome in these cases.

\section{Materials and Methods}

Study Population: A prospective case control study was conducted in the Departments of Microbiology and Pediatrics, University College of Medical Sciences (UCMS) and Guru Tegh Bahadur (GTB) Hospital, a tertiary care hospital in Delhi over a period of one year. Thirty newborn babies $\geq 31$ weeks of gestation with Apgar score $<8$ at 1 minute after birth with perinatal asphyxia were enrolled as subjects in this study (study group), along with 30 age and sex matched healthy controls (control group).

Approval of Institutional Ethical Committee of UCMS \& GTB Hospital, Delhi was taken. Parental consent was obtained for every neonate before inclusion in the study.

Inclusion criteria: An Apgar score of 8 or less at 1 minute and Gestational age $>31$ weeks.

Exclusion criteria: Maternal temperature during labour $>38^{\circ} \mathrm{C}$, foul smelling amniotic fluid, congenital or perinatal infections, including histologic or clinical chorioamnionitis, congenital malformations, metabolic disorders, maternal drug addiction, UTI during admission for delivery, positive body fluid culture or babies who expired after enrolment within 48 hours.

Sample collection and processing: Venous blood (approximately) 2-3 $\mathrm{ml}$ was collected at birth (within 6 hours of delivery) and at $48( \pm 2)$ hours of life under aseptic precautions. Sera were separated and stored at $-20^{\circ} \mathrm{C}$ for estimation of serum IL-6 levels using Diaclone IL-6 solid phase sandwich ELISA kit (Diaclone SAS, France).

Routine investigations including blood culture, serum creatinine, sodium, potassium, calcium and arterial blood gas were done at the time of initial evaluation (within 6-8 hrs of birth) and recorded in the case record form of each patient.

\section{Data management and statistical analysis}

The mean of continuous variables was compared among various groups, using paired or unpaired t-test/repeated measure ANOVA as applicable. If the data was of nonnormal distribution then non-parametric tests were applied. $P$ value $<0.05$ was considered statistically significant.

\section{Result}

This prospective case control study was carried among 30 newborn babies with perinatal asphyxia along with age and sex matched healthy controls. Out of the 30 neonates in the study group $18(60 \%)$ were males and the male to female ratio was 3:2. $21(70 \%)$ babies among the control group were males. Among the cases 24 (80\%) babies were born through normal vaginal delivery whereas $25(83.33 \%)$ control babies were vaginally delivered. The gender or the mode of delivery was statistically not significant among the study and the control groups indicating that the two groups were well matched ( $p$ value $=0.417$ ). Out of the 30 cases $5(16.67 \%)$ weighed less than $1.5 \mathrm{Kg}, 11(36.67 \%)$ weighed between 1.5 to $2.49 \mathrm{Kg}$ and 14(46.67\%) weighed more than or equal to $2.5 \mathrm{kgs}$. Among the control group $18(60 \%)$ neonates were $\geq 2.5 \mathrm{Kg}$ in weight and $12(40 \%)$ neonates were between 1.5-2.5 Kg at birth (Fig 1). Out of total cases $15(50 \%)$ were delivered at term (37-41 weeks of gestation), $14(46.67 \%)$ were preterm and only $1(3.33 \%)$ was delivered after 41 weeks of gestation. Out of 30 controls 24(80\%) neonates were delivered at 36-41 weeks of gestation, while $13.33 \%$ and $6.67 \%$ were delivered preterm and post term respectively (Fig 2).

On clinical assessment 29 (96.67\%) of the cases had clear liquor while the remaining $3.33 \%$ had meconium stained liquor. All the cases had respiratory distress. Out of the 30 cases, 7 (23.33\%), 18(60\%) and 5(16.67\%) had mild, moderate and severe perinatal asphyxia respectively. Among control group clear liquor was seen at the time of delivery among all the 30 neonates and none of these neonates had respiratory distress or sepsis (Table 1). Of total 30 cases, $5(16.67 \%)$ babies required ventilatory support. $21(70 \%)$ of these neonates were prescribed antibiotics mainly piperacillin + tazobactam as a protocol for such conditions.

Among the cases, 14(46.67\%) had increased serum creatinine level and in $1(3.33 \%)$ neonate both serum sodium and potassium levels were raised. Increase in CRP levels was seen in $27(90 \%)$ cases, while acidosis was observed in $25(83.3 \%)$ cases. In 26 (86.67\%), 29 (96.67\%), $16(53.33 \%), 14(46.67 \%)$ neonates among the study group sodium, potassium, creatinine and calcium levels respectively were within the normal range. All the laboratory parameters were within normal limits in the 30 control neonates and no bacteria was isolated from their blood samples.

The mean levels of IL-6 were $158.09 \pm 63.76 \mathrm{pg} / \mathrm{ml}$ and $41.57 \pm 71.23 \mathrm{pg} / \mathrm{ml}$ at birth in the study and the control group respectively $(\mathrm{p}=0.001)$. The levels at 48 hours were $187.96 \pm 30.31 \mathrm{pg} / \mathrm{ml}$ and $24.54 \pm 58.74 \mathrm{pg} / \mathrm{ml}$ in the study and control group respectively $(\mathrm{p}=0.001)$. The IL-6 levels significantly increased by 48 hours in the study group $(\mathrm{p}=0.019)$. Amongst the control group neonates, the IL-6 levels were statistically not significant at birth and 48 hour $(\mathrm{p}=0.405)$ (Table 2). 
Table 3 depicts that the median IL-6 levels both at birth and 48 hours were statistically not significant $(p=0.268$, $\mathrm{p}=0.633$ respectively) among the mild, moderate and severely asphyxiated neonates. In the different degree of severity of perinatal asphyxia, the levels of median IL-6 at birth and 48 hours were statistically not significant (mild $\mathrm{p}=0.068$, moderate $\mathrm{p}=0.062$, severe $\mathrm{p}=0.180$ ).

The median IL-6 levels in the study and the control group were $196.40 \mathrm{pg} / \mathrm{ml}$ and $4.17 \mathrm{pg} / \mathrm{ml}$ respectively at birth. (Table 3) The median levels in the study group at birth were 47 fold higher than those of the control group.
The standard deviation of IL-6 levels among the severe perinatal asphyxiated neonates at birth and 48 hours was less [9.39 (at birth) and 17.27 (at 48 hour)] suggesting that IL-6 levels were high in those severe cases even at birth and remained high at 48 hour as compared to mild or moderately asphyxiated neonates.

Results of Wilcoxon signed ranks test done for two dependent variables showed that, at 48 hours in 12 (40\%) of the neonates in the study group a rise in IL- 6 level was observed. IL-6 levels decreased in $5(16.6 \%)$ neonates at 48 hours whereas the levels remained same in $13(43.3 \%)$ of these neonates at birth and 48 hours.

Table 1 : Distribution of study subjects on basis of clinical assessment.

\begin{tabular}{|c|c|c|c|}
\hline \multicolumn{2}{|c|}{ Findings on clinical assessment } & Study group $\mathbf{n = 3 0 ~ ( \% ) ~}$ & Control group $\mathbf{n = 3 0 ~ ( \% ) ~}$ \\
\hline \multirow{2}{*}{ Type of liquor } & Clear & $29(96.6)$ & $30(100)$ \\
\cline { 2 - 4 } & MSL & $01(3.3)$ & 0 \\
\hline \multirow{2}{*}{$\begin{array}{c}\text { Severity of perinatal } \\
\text { asphyxia }\end{array}$} & Mild & $7(23.3)$ & 0 \\
\cline { 2 - 4 } & Moderate & $18(60)$ & 0 \\
\hline \multicolumn{2}{|r|}{ Respiratory distress } & $5(16.6)$ & 0 \\
\hline
\end{tabular}

MSL - meconium stained liquor

Severity of perinatal asphyxia (based on Apgar score) - normal $\geq 8$, mild 6-7, moderate 3-5, and severe $<3$

Table 2 : IL-6 levels in the study and control group at birth and at 48 hours after birth.

\begin{tabular}{|c|c|c|c|c|}
\hline Group & Number of cases & $\begin{array}{c}\text { IL-6 levels (mean pg/ } \\
\text { ml) At birth* }\end{array}$ & $\begin{array}{c}\text { IL-6 levels (mean pg/ml) } \\
\text { 48 hour }\end{array}$ & p value \\
\hline Study & 30 & $158.09 \pm 63.76$ & $187.95 \pm 30.31$ & 0.019 (significant) \\
\hline Control & 30 & $41.57 \pm 71.23$ & $24.54 \pm 58.74$ & 0.405 (not significant) \\
\hline$p$ value & & 0.001 (significant) & 0.001 (significant) & \\
\hline
\end{tabular}

*At birth - (within 6 hours of delivery)

Table 3 : IL-6 Levels in various degrees of severity of perinatal asphyxia.

\begin{tabular}{|c|c|c|c|c|c|c|c|c|}
\hline & \multicolumn{2}{|c|}{$\begin{array}{l}\text { Mild Perinatal } \\
\text { Asphyxia } \\
(n=7)\end{array}$} & \multicolumn{2}{|c|}{$\begin{array}{l}\text { Moderate Perinatal } \\
\text { Asphyxia } \\
(n=18)\end{array}$} & \multicolumn{2}{|c|}{$\begin{array}{l}\text { Severe Perinatal } \\
\text { Asphyxia } \\
(n=5)\end{array}$} & \multicolumn{2}{|c|}{$\begin{array}{l}\text { Control } \\
(n=30)\end{array}$} \\
\hline & At Birth & $48 \mathrm{hr}$ & At Birth & $48 \mathrm{hr}$ & At Birth & $48 \mathrm{hr}$ & At Birth & $48 \mathrm{hr}$ \\
\hline Median (pg/ml) & 145.70 & $\geq 200$ & 192 & $\geq 200$ & $\geq 200$ & $\geq 200$ & 4.17 & 2.98 \\
\hline Range (pg/ml) & 158.23 & 123.66 & 193.71 & 100.34 & 21.0 & 39.90 & 222.05 & 221.55 \\
\hline Minimum level (pg/ml) & 41.77 & 76.34 & 6.30 & 99.66 & 179.0 & 160.10 & -9.2 & -8.64 \\
\hline Maximum level (pg/ml) & $\geq 200$ & $\geq 200$ & $\geq 200$ & $\geq 200$ & $\geq 200$ & $\geq 200$ & 212.85 & 212.91 \\
\hline \multirow{2}{*}{ Mean (pg/ml) } & 139.45 & 182.33 & 154.86 & 189.54 & 195.80 & 190.12 & 41.57 & 24.54 \\
\hline & \multicolumn{2}{|c|}{$p=0.068$} & \multicolumn{2}{|c|}{$p=0.062$} & \multicolumn{2}{|c|}{$p=0.180$} & \multicolumn{2}{|c|}{$p=0.405$} \\
\hline Standard deviation & 69.22 & 46.73 & 68.20 & 26.63 & 195.80 & 190.12 & 71.23 & 58.73 \\
\hline
\end{tabular}


$\square<1.5 \mathrm{kgs} \square 1.5-2.49 \mathrm{kgs} \square \geq 2.5 \mathrm{kgs}$

$\square<1.5 \mathrm{kgs} \square 1.5-2.49 \mathrm{kgs} \square \geq 2.5 \mathrm{kgs}$
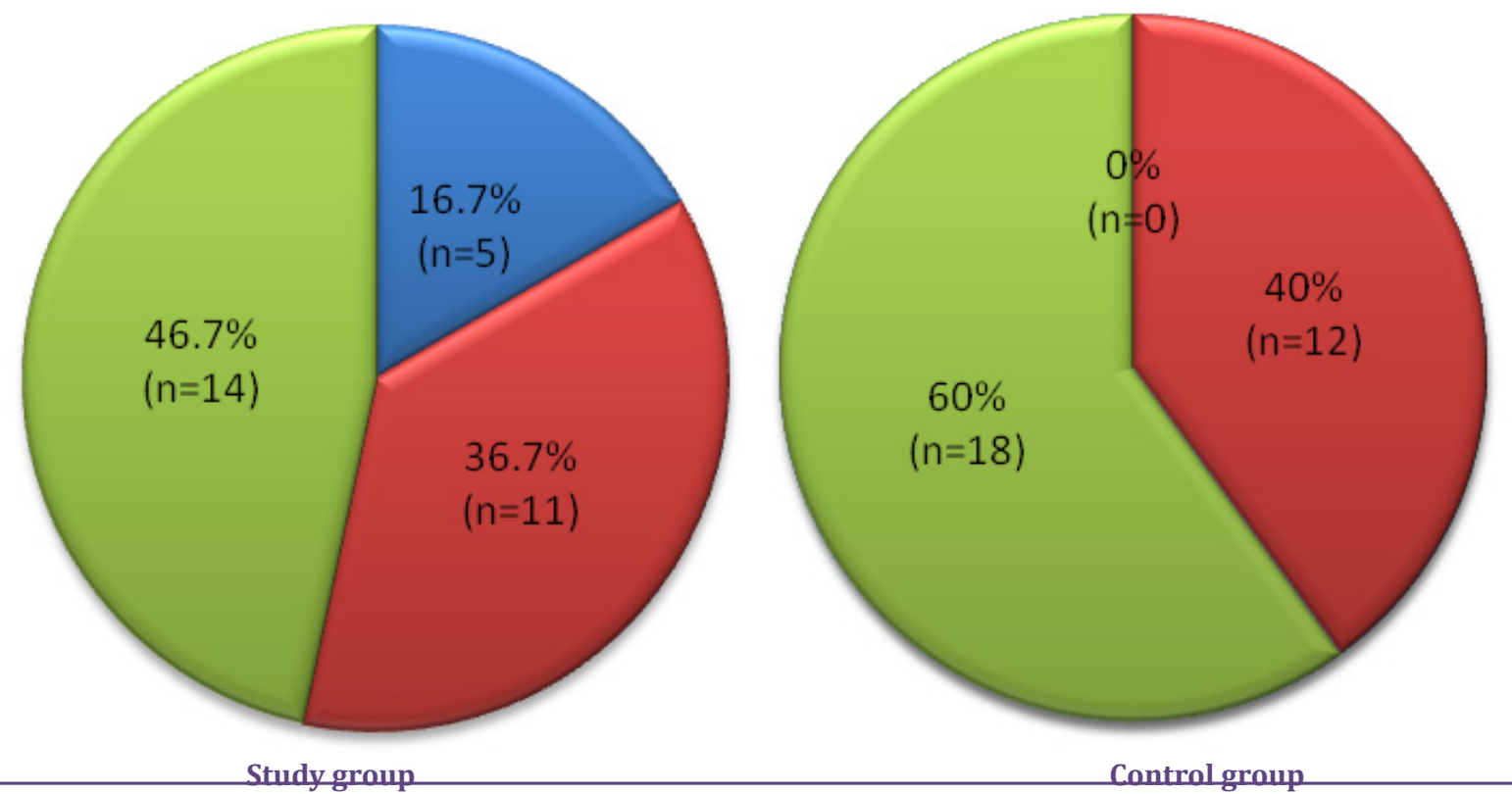

Fig. 1: Distribution on the basis of birth weight.

$31-36$ wks $\square 37-41$ wks $\square>41$ wks

③1-36wks $\square 37-41 w k s \square>41 w k s$

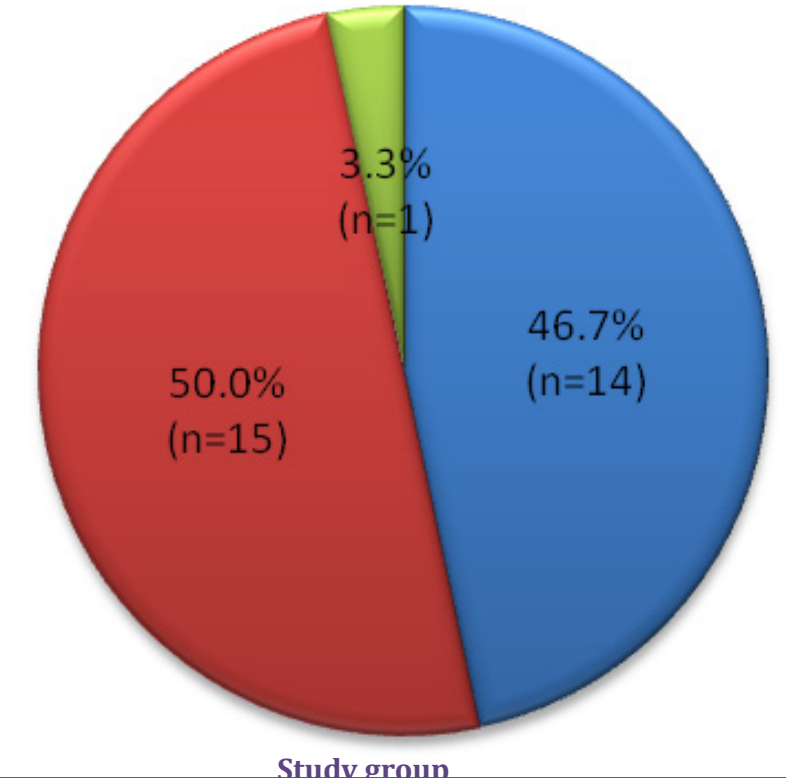

Study group

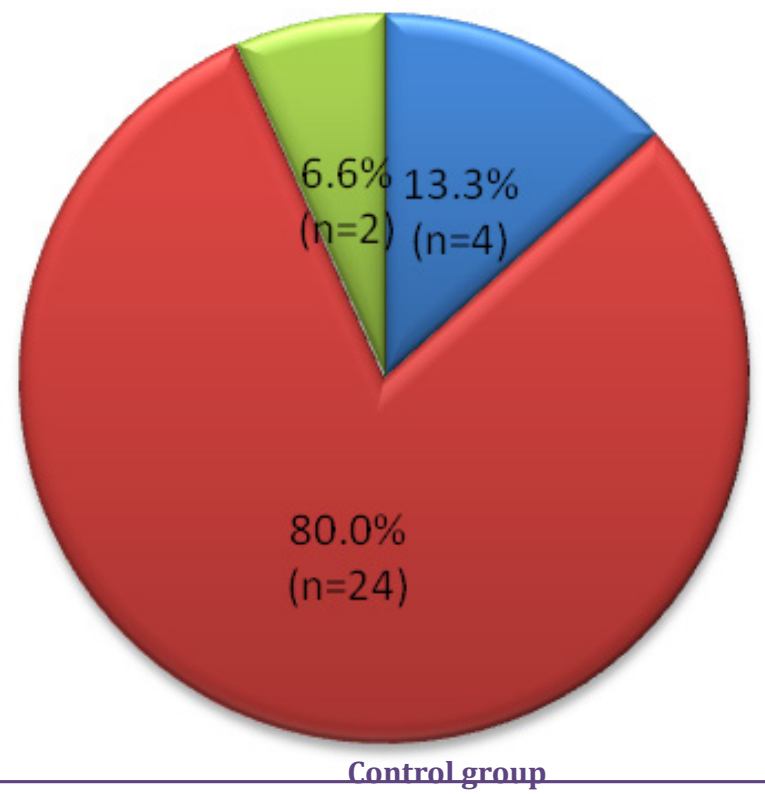

Fig. 2 : Distribution on the basis of period of gestation 


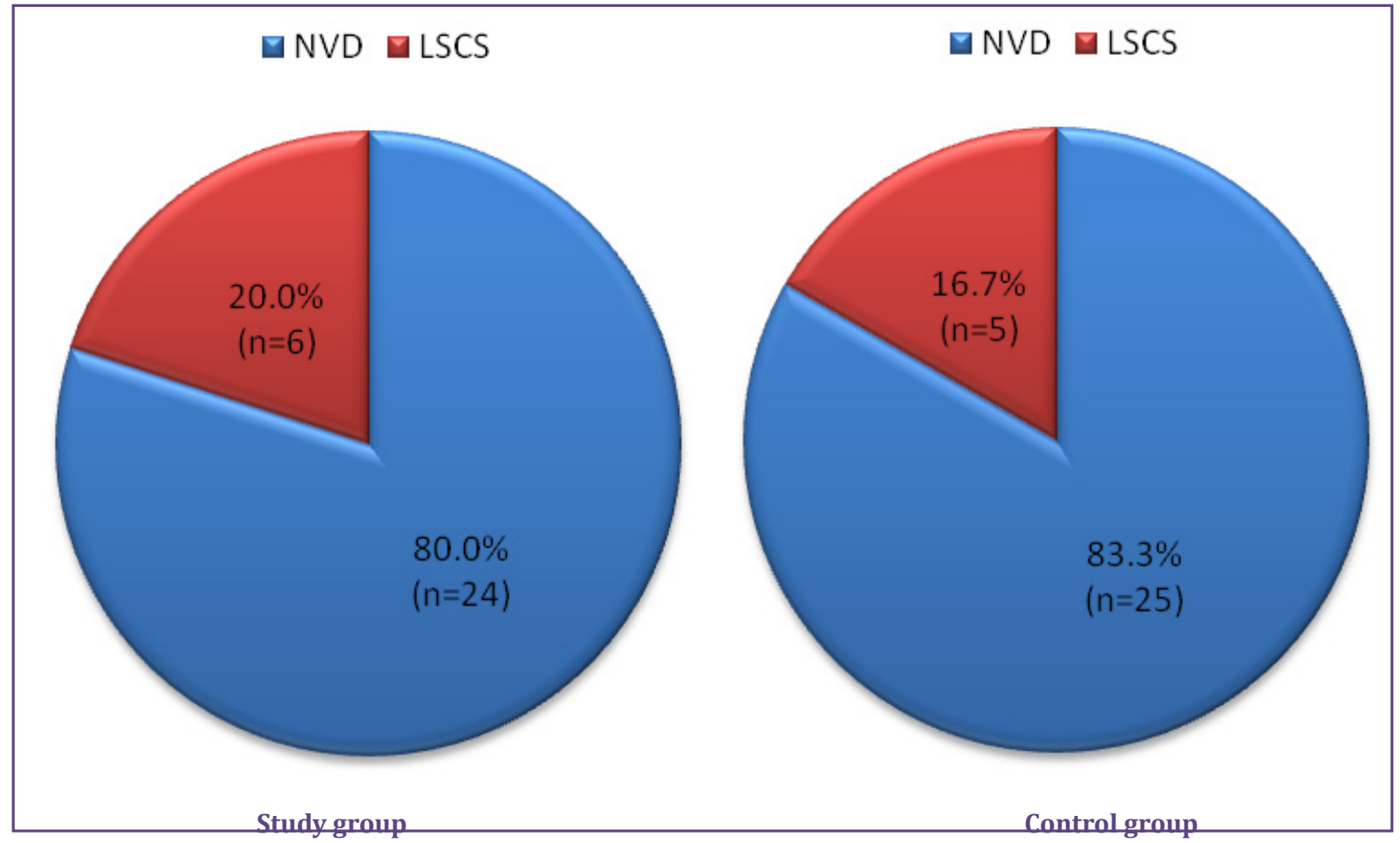

Fig. 3 : Distribution according to mode of delivery.

\section{Discussion}

Out of the 30 study group neonates, $18(60 \%)$ were male and $12(40 \%)$ were female babies having a sex ratio of $3: 2$. Boskabadi et al conducted a similar study in which 20 out of $33(60.6 \%)$ were males.[9]

Out of 30 cases and 30 controls, 24(80\%) and 25(85.5\%) of the cases and controls respectively were delivered by normal vaginal route and $6(20 \%)$ and $5(16.6 \%)$ of the cases and controls were delivered through lower segment cesarean section (LSCS) respectively. (Fig.3). Boskabadi et al did a similar study on IL-6 estimation on 12 out of 33 (36\%) neonates delivered by vaginal route and 21 out of $33(63.6 \%)$ neonates delivered by LSCS.[9] In this study $14(46.7 \%)$ of cases were delivered at 31-36 weeks of gestation, $15(50 \%)$ at $37-41$ weeks of gestation and only 1 case was delivered $>41$ weeks of gestation compared to $24(80 \%)$ of the control group neonates delivered at term and $4(13.3 \%)$ of the control group babies were delivered preterm ( $<37$ weeks). Respiratory distress was seen in all the $30(100 \%)$ of cases. None of the control group newborn babies had respiratory problem. Boskabadi et al from Iran reported that in their study only $51.6 \%$ of neonates had respiratory problems and 12(36\%) were delivered by vaginal route.[9] $6(20 \%)$ of the study group babies were weighing $<1.5 \mathrm{~kg}$ at birth. $14(47 \%)$ and $18(60 \%)$ of the study and control group babies weighed $>2.5 \mathrm{~kg}$.
Any of these factors, namely, gender, mode of delivery, birth weight or period of gestation could be contributing to perinatal asphyxia and rise in levels IL-6.

CRP serum values were significantly higher in the infected neonates than in the asphyxiated or control subjects.[10] CRP levels are raised in both bacterial and viral infections but more in bacterial infection. Ferritin level is elevated mainly in viral infections. Procalcitonin has come up as a good biomarker in infectious inflammation.[11]

\section{IL-6 ESTIMATION.}

At birth IL-6 levels were $158.09 \pm 63.76 \mathrm{pg} / \mathrm{ml}$ and $41.57 \pm 71.23 \mathrm{pg} / \mathrm{ml}$ in the study and control groups respectively $(\mathrm{p}=0.001)$ and at 48 hours $187.95 \pm 30.31 \mathrm{pg} /$ $\mathrm{ml}$ and $24.54 \pm 58.74 \mathrm{pg} / \mathrm{ml}$ in the study and control group respectively $(\mathrm{p}=0.001)$. High levels $(>141.7 \mathrm{pg} / \mathrm{ml})$ of IL-6 were observed in 5/30 (16.6\%) of the control group neonates at birth, as a result the mean IL-6 levels were $41.57 \pm 71.23$ at birth whereas the median level was 4.17 at birth. In all these babies the levels waned by 48 hours to $<47.56 \mathrm{pg} / \mathrm{ml}$ and moreover in 3 of these 5 neonates they fell below the detectable levels suggesting that these high levels at birth could be due to raised maternal IL-6 levels which is reported during parturition.[12]

Boskabadi et al in their study reported that serum IL-6 concentrations increased considerably after birth asphyxia 
and the increase were associated with severity of perinatal asphyxia. Furthermore, same study has reported a 94.5\% sensitivity, $97.7 \%$ specificity, $97.0 \%$ positive predictive value and $95.0 \%$ negative predictive value of IL-6 in predicting the development of asphyxia for concentrations greater than $12.5 \mathrm{pg} / \mathrm{mL}$.[9]

Karin Sävman et al in their study reported, IL-6 levels of $250(35-542.5) \mathrm{pg} / \mathrm{ml}$ in study group compared with 0 (0$18.8) \mathrm{pg} / \mathrm{ml}$ in the control group $(\mathrm{p}=0.001)$ in cases of perinatal asphyxia.[13] Chiesa et al from Italy also reported that IL-6 levels are elevated in term neonates with perinatal asphyxia.[14] Aley et al also reported significantly raised IL-6 concentrations among asphyxiated neonates. IL-6 concentrations were also related to neurological outcome at the end of first month.[15] All these studies suggest that IL-6 is sensitive to perinatal asphyxia, and in almost all studies, raised levels of IL-6 was observed.

\section{Conclusion}

IL-6 levels were significantly raised at birth (within 6 hours of delivery) and at 48 hours in

asphyxiated neonates compared to gestational age and sex matched healthy neonates. Hence

IL-6 could be used as a serological marker of perinatal asphyxia.

\section{Reference}

1. Cowan F, Rutherford M, Groenendaal F, Eken P, Mercuri E, Bydder GM, Meiners LC, Dubowitz LM, de Vries LS. Origin and timing of brain lesions in term infants with neonatal encephalopathy. Lancet 2003; 361: 736-42.

2. De Costello LAM, Manandhar DS. Perinatal asphyxia in less developed countries. Arch Dis Child Fetal Neonatal Ed 1994; 71:F1-3.

3. National Neonatal-Perinatal Database (2002-03). New Delhi, India: National Neonatology Forum and Indian Council of Medical Research.
4. Kliegman RM, Stanton BF, St. Geme JW, Schor NF, Berhman RE. Nelson Textbook of Pediatrics , 19th ed. Philadelphia: Elsevier Saunders; 2011.

5. Volpe JJ. Neurology of the Newborn, 3rd Ed. WB Saunders, Philadelphia, 1995:pp 876-884.

6. Kjellmer I, Hagberg H 1994 Perinatal brain damage, excitatory amino acids and oxygen derived free radicals. In: Geijn HPV and Copray FJA (eds). A Critical Appraisal of Fetal Surveillance. Elsevier, Amsterdam, pp 604-614.

7. Vannucci RC. Experimental biology of cerebral hypoxiaischemia: relation to perinatal brain damage. Pediatr Res 1990;27:317-326.

8. Johnston MV. Neurotransmitters and vulnerability of the developing brain. Brain Dev 1995;17:301-306.

9. Boskabadi H, Afshari JT, Ghayour-Mobarhan M, Maamouri G, Shakeri MT, Sahebkar A, et al. Association between serum interleukin-6 levels and severity of perinatal asphyxia. Asian Biomed 2010;4:79-85

10. Xanthou M, Fotopoulos S, Mouchtouri A, Lipsou N, Zika I, Sarafidou J. Inflammatory mediators in perinatal asphyxia and infection. Acta Paediatr Suppl. 2002;91(438):92-7.

11. Slaats J, Oever J, Veerdonk FL, Netea MG. IL-1 $\beta /$ IL-6/ CRP and IL-18/ferritin: Distinct Inflammatory Programs in Infections. PLoS Pathog 2016; 12(12): e1005973

12. Arntzen KJ, Lien E, Austgulen R. Maternal serum levels of interleukin- 6 and clinical characteristics of normal delivery at term. ActaObstetGynecolScand 1997;76(1):55-60.

13. Sävman K, Blennow M, Gustafson K, Tarkowski E, Hagberg H. Cytokine response in cerebrospinal fluid after birth asphyxia. Pediatr Res 1998;43(6):746-51.

14. Chiesa C, Pellegrini G, Panero A, De Luca T, Assumma M, Signore F, Pacifico L. Umbilical cord interleukin-6 levels are elevated in term neonates with perinatal asphyxia. Eur J Clin Invest 2003;33(4):352-8.

15. Aly H, Khashabab MT, El-Ayoutyb M, El-Sayedb M, Hasanein BM. IL-1 $\beta$, IL-6 and TNF-a and outcomes of neonatal hypoxic ischemic encephalopathy. Brain Development 2006; 28:178-82.

*Corresponding author:

Dr. Mohd Tajuddin, Flat No. 102, Ilahi apartment, C212, Shaheen Bagh, Abul Fazal Enc Part 2, Okhla, New Delhi-110025

Phone: +91 9560504770

Email: taj.ucms@gmail.com

Financial or other Competing Interests: None. 